\title{
Changes in Vietnamese Male Smokers' Reactions Towards New Pictorial Cigarette Pack Warnings Over Time
}

\author{
Tran Thu Ngan ${ }^{1 *}$, Le Vu Anh${ }^{2}$, Nguyen Thi Tuyet $\mathrm{My}^{1}$, Nguyen Ngoc Bich ${ }^{2,3}$
}

\begin{abstract}
Printing of pictorial health warnings (PHWs) on cigarette packages became obligatory by the Vietnam Law on Prevention and Control of Tobacco Harm in May 2013. Literature from high-income countries suggests that PHWs motivate smokers to quit smoking although their long-term effects have been questioned due to reduction of impact over time. This study aimed to assess the salience of PHWs and smokers' reactions towards PHWs over time. In May 2014 and May 2015, a cross-sectional questionnaire-based household survey was administered to respectively 1,462 and 1,509 Vietnamese male smokers aged 18 to 35 . The result showed that salience of the PHWs 2 years after the implementation was higher than at the point of 1 year after the implementation. The proportion of respondents who tried to avoid noting the PHWs was reduced from $35 \%$ in wave 1 to $23 \%$ in wave 2. However, "Tried to avoid looking/thinking about the PHWs" increased 1.5 times the odds of presenting quit intention compared to those respondents who did not try to avoid looking/thinking about the PHWs (OR=1.5; 95\% CI: 1.2-2.0). In conclusion, avoidance regarding PHWs may not work as a barrier when aiming at a higher level of quit intention. Salience of the PHWs may increase in the period shortly after their introduction onto packs but can be expected to decrease with time. In other words, it might be advisable to change or renew PHWs after a period of implementation to maintain their beneficial effects.
\end{abstract}

Keywords: Pictorial/graphic health warning - salience - reaction - intention to quit - smoking cessation - LMICs

Asian Pac J Cancer Prev, 17 Tobacco Prevention and Control in Vietnam Suppl, 71-78

\section{Introduction}

Tobacco is the only legal consumer product that can kill people when it is used in accordance to manufacturer's instruction (World Health Organization, 2008). Vietnam is in the top 15 countries which has the highest proportion of male smokers in the world (47.4\%) (Vietnam Ministry of Health et al., 2010). In Vietnam, the proportion of annual deaths attributable to tobacco is $21 \%$ among male (319 deaths per 100,000) and 12\% among women (142 deaths per 100,000) (Tan Yen Lian and Ulysses Dorotheo, 2013).

Tobacco industries use striking colors, distinctive fonts and carefully crafted materials to make cigarette packages highly attractive, especially among young people who constitute the primary source of new customers. To take away the advantages of attractive cigarette packet, health warning on cigarette packet is a prominent direct mean of communicating (Hammond, 2007; Hammond, 2009; Prakit Vathesatogkit, 2010; Hammond, 2011). This type of intervention is also considered as one of the most cost-effective health communication channels available in the field of tobacco control (Hammond, 2007; Hammond, 2009; International Tobacco Control Policy Evaluation Project, 2009; Prakit Vathesatogkit,
2010; Hammond, 2011). Hence, Article 11 of the World Health Organization (WHO) Framework Convention on Tobacco Control (FCTC) requires all Member Parties to implement the health warnings on cigarette pack (World Health Organization, 2005).

Results from studies in both high, middle and low income countries indicated that pictorial health warnings (PHWs) have significantly higher effectiveness compared to text-only warnings (Nguyen Ngoc Bich and Do Minh Son, 2006; O'Hegarty et al., 2007; Borland R et al., 2009a; Vardavas et al., 2009; Fathelrahman et al., 2010; EltonMarshall et al., 2015; Sychareun et al., 2015). This is the reason why, in FCTC, WHO also recommends the Member Parties to use large pictorial health warnings instead of text-based warnings (World Health Organization, 2005).

In compliance with FCTC requirements and recommendations, 2012 Vietnamese Law on Prevention and Control of Tobacco Harms (2012 TC Law) mandates the printing of PHWs (Figure 1), which cover $50 \%$ of all principal display surfaces of a cigarette pack (National Assembly of Vietnam, 2012). The 2012 TC Law in general and obligation of printing PHWs in particular took effect on May 2013 (National Assembly of Vietnam, 2012).

According to Australian research, response to the

${ }^{1}$ Centre for Population Health Sciences, Hanoi School of Public Health, ${ }^{2}$ Vietnam Public Health Association, ${ }^{3}$ Faculty of Environmental and Occupational Health, Hanoi School of Public Health, Hanoi, Viet Nam*For correspondence: ttn2@ hsph.edu.vn or ngantran. hsph@gmail.com 
new warnings would reach its peak levels shortly after the implementation (Borland and Hill, 1997). After that peak, the warnings are supposed to lose some of their impact with time (Hammond et al., 2006; Borland et al., 2009b; Miller et al., 2009). For example, new set of PHWs was introduced in Australia in 2006; and research results reported that health warnings were named as a motivator to quit by $16.4 \%, 19.4 \%$ and $15.2 \%$ in 2004,2007 and 2010 respectively (or before implementation, shortly after implementation and long time after implementation respectively) (Australian Institute of Health and Welfare, 2004; Australian Institute of Health and Welfare, 2010). The extent of PHW wear-out is differ from country to country and depends on the specific PHWs implemented (Moodie et al., 2013; White et al., 2014; Auemaneekul et al., 2015; Li et al., 2015). Hence, it is important to understand the trend of change in 1) PHWs' salience and 2) reaction of smokers towards the PHWs as well as influence of that trend on smokers' intention to quit.

\section{Materials and Methods}

\section{Design of the study}

This is a repeated cross-sectional study in which wave 1 was conducted in May 2014 and wave 2 was conducted in May 2015 or in other word, 1 year and 2 year respectively after the introduction of PHWs in Vietnam. Study location and sample size of the two waves were the same but the respondents were different (not follow-up respondents). Targeted respondents were male smokers aged from 18 to 35 years who have seen the PHWs at least once. We included only male smokers in this study due to relatively low smoking prevalence (1.4\%) among females in Vietnam (Vietnam Ministry of Health et al., 2010).

\section{Sample size and sampling method}

Vietnam is divided into 3 main geographic strata as the North, the Central and the South. In order to achieve a representative sample, two provinces were randomly selected from each geographic stratum. Afterwards, 5 urban communes and 5 rural communes were selected from each province using probability proportional to size sampling. The sample size was distributed equally between urban and rural areas and among 6 study sites. In the 1st wave on May 2013, 1480 male smokers completed the interview. In the 2 nd wave 1 year later, 1509 male smokers were interviewed.

Four screening questions corresponding to 3 inclusion criteria ("smoker", "aged 18-35 years" and "have seen PHWs at least once") were used to check the eligibility of respondents. The definition of a smoker was as described by the Global Adult Tobacco Survey (GATS) in which smokers were defined as individual who 1) had smoked at least one cigarette in the last week prior to the interview in the present study and 2) had smoked more than 100 cigarettes in his life time. Eligible respondents were then face-to-face interviewed using a structured questionnaire.

\section{The survey questionnaire}

At first, the survey questionnaire was developed in English. Translation and back-translation were done to ensure the coherence between Vietnamese and English version of the questionnaire. A pilot was launched to pretest the questionnaire before finalizing it.

\section{Dependent variable - Intention to quit}

In this study, our dependent or outcome variable was the respondents' self-reported intention to stop smoking. This variable was derived from the question "Are you planning to quit smoking?" with a binary answer Yes or No.

\section{Independent variables}

Salience of the PHWs was measured through two items:

i). Notice ("In the last month, how often have you noticed the PHWs on cigarette packages?")

ii). Attention ("In the last month, how often have you looked closely at the pictures and read the enclosed warning messages printed on the cigarette packages?") Responses were given according to a three-point Likert scale ("Always", "Often", "Once in a while"). Based on respondents' answer, salience measure was computed (range $=1-3$, Cronbach's $=0.78$ in both waves).

\section{Avoidant behaviors}

Whether the respondent make any effort to avoid the PHWs or not were derived from the question "In the last month, have you made any effort to avoid looking at or thinking about the pictorial warning labels?". If the answer is yes, respondents were asked "What did you do to avoid the pictorial warning labels?" in order to understand their specific avoidant behaviors.

Selection of pack with and without PHW

To understand smokers' purchase behavior in the transition period (when both pack with and without PHWs are presented), respondents were asked for their choice of cigarette pack in three hypothetical scenarios that can happen at the tobacco shop/vender as following:

i).Customer's preferred brand has both the pack with and without PHW, price of two types are the same

ii) Customer's preferred brand has both the pack with and without PHW, price of the pack that do not have PHW is higher
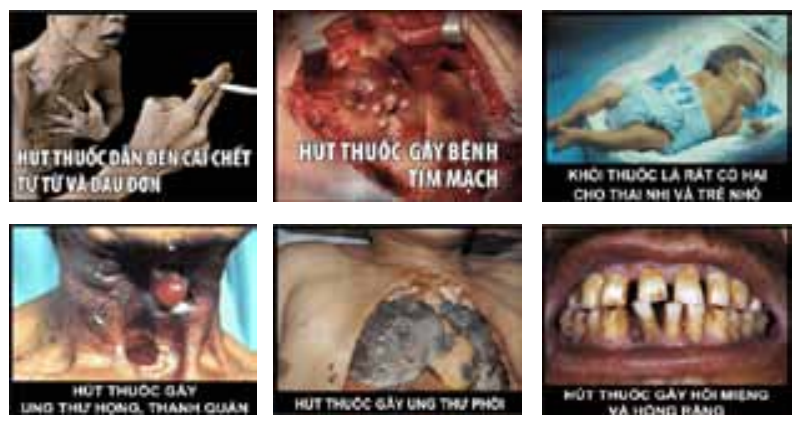

Figure 1. Pictorial health warning printed on cigarette packages in Vietnam since May 2013. From left to right, up to down: (1) Smoking leads to death slowly and painfully; (2) Smoking causes heart diseases; (3) Cigarette smoke is very harmful to fetus and young children; (4) Smoking causes throat and laryngeal cancer; (5) Smoking causes lung cancer; (6) Smoking causes bad breath and damaged tooth 
Changes in Vietnamese Male Smokers' Reactions Towards the New Pictorial Cigarette Pack Warnings Over Time

iii) Customer's preferred brand has only the packages with pictorial health warning

The survey also considered and assessed daily cigarette consumption, number of years as a smoker, level of concern about health consequences of smoking, quitting history, sex, education, and age group.

\section{Ethical consideration}

The study received ethical clearance from Institutional Review Board of Hanoi School of Public Health in Vietnam. After an explanation of the study outlines a written informed consent was obtained from the respondent before starting the interview.

\section{Statistical analysis}

Data was analyzed using SPSS software (version 20.0). Significant level used in the tests was 0.05. In the bivariate analysis chi-square test and crude odds ratio (OR) were used to measure the association between main measures and outcome as intention to quit smoking. In the multivariate analysis, logistic regression analysis (LRA) was used to adjust for potential confounding. All co-variables included in the LRA model were statistically significantly associated with the outcome.

\section{Results}

\section{Characteristics of the sample}

In wave 1 , out of 1480 smokers completed the questionnaire, 18 cases were excluded during cleaning process due to absence or incomplete data of key variables. Thus, in wave 1, 1462 smokers were included in analyses. The results of a statistical comparison of the individuals included in the analysis and those who were excluded showed that there were no statistical significant differences between the two groups in terms of, age, occupation and educational level (results of chi-square test, $\mathrm{p}>0.05$ for all tests). In wave 2, all 1509 smokers who completed the survey were included in analyses.

An overall description of the respondents, including demographic and smoking behaviors characteristics are presented in Table 1 . The study was conducted on smokers aged 18-35, thus mean age of participated smokers was only 27.3 years old. Around $21 \%$ of the respondents had high education level ( $>12$ years). The mean age for smoking debut was 18.83 years old. The youngest smokers started their habit at the age of 7 years old. Mean period of being a smoker was 8.48 years. The longest time of smoking was 30 years in wave 1 and 25 years in wave 2. Proportion of smokers who had smoked for more than 15 years (doubled the average years of being smokers of the sample) was $13.9 \%$. Daily smokers accounted for approximately $78 \%$ of the sample size. Among daily smokers, the vast majority $(81.7 \%)$ smoked more than 5 cigarettes per day.

There were still more than two third of respondents $(62.5 \%)$ reported that they are not worried at all or worried a little about the health consequences of smoking.

Table 1. Demographic and Smoking Behaviors Characteristics of the Sample Across 2 Waves of the Study

\begin{tabular}{|c|c|c|c|c|}
\hline & Total & Wave 1 & Wave 2 & p-value \\
\hline No. of interviewed smokers & 2971 & 1462 & 1509 & - \\
\hline Mean age in years & 27.3 & 27.4 & 27.2 & NS** \\
\hline Education ( $>12$ years) & 21.0 & 21.6 & 20.4 & NS* \\
\hline Mean age when started smoking & 18.8 & 18.7 & 18.9 & NS** \\
\hline Mean years as a smoker & 8.5 & 8.7 & 8.3 & $0.027 * *$ \\
\hline Proportion of individuals who smoke daily (\%) & 78.4 & 79.8 & 76.9 & NS* \\
\hline \multicolumn{5}{|c|}{ No. of cigarettes smoke per day (among daily smokers) } \\
\hline 5 cigarettes or less & 20.9 & 23.0 & 18.8 & $0.001 *$ \\
\hline From 6 to 14 cigarettes & 43.3 & 39.7 & 46.9 & \\
\hline 15 cigarettes or more & 35.8 & 37.3 & 34.3 & \\
\hline \multicolumn{5}{|l|}{ Worried about the health consequences of smoking } \\
\hline Not at all worried & 17.5 & 19.0 & 16.1 & $<0.001^{*}$ \\
\hline A little worried & 45.0 & 45.4 & 44.6 & \\
\hline Moderately worried & 21.7 & 23.0 & 20.5 & \\
\hline Very worried & 15.8 & 12.7 & 18.8 & \\
\hline Ever made a quit attempt & 44.4 & 42.4 & 46.3 & $0.032 *$ \\
\hline Mean quit attempt did last year & 2.1 & 2.4 & 1.9 & NS** \\
\hline \multicolumn{5}{|l|}{ Notice the PHWs on cigarette packages } \\
\hline Once in a while & 35.3 & 36.7 & 34.0 & $<0.001^{*}$ \\
\hline Often & 44.4 & 47.4 & 41.5 & \\
\hline Always & 20.4 & 16.0 & 24.6 & \\
\hline \multicolumn{5}{|c|}{ Look closely at the pictures and read the enclosed warning messages printed on the cigarette packages } \\
\hline Once in a while & 31.2 & 29.2 & 32.9 & $<0.001 *$ \\
\hline Often & 50.7 & 55.4 & 46.6 & \\
\hline Always & 18.1 & 15.4 & 20.5 & \\
\hline
\end{tabular}

NS: Not significant; * Results of chi-square test comparing between wave 1 and wave $2 ; * *$ Results of independent t-test comparing between wave 1 and wave $2 "$ 
Proportion of people who are worried at moderate level or very worried was about $22 \%$ and $15.8 \%$ respectively.

Proportion of smokers who ever made a quit attempt in general is $44.4 \%$. This proportion had increased from $42.4 \%$ at wave 1 to $46.3 \%$ at wave 2 . Average number of quit attempt done last year was reported at 2.42 in wave 1 and 1.87 at wave 2 . The difference between wave 1 and wave 2 was statistically significant.

\section{Salience of the PHWs}

Table 1 also illustrated the salience of PHWs over time. In wave $1-1$ year after the introduction of PHWs $-16.0 \%$ and $15.4 \%$ of smokers notice or read the PHWs all the time respectively. In wave 2 - 1 year after wave 1 and 2 years after the implementation - the similar rate increased to $24.6 \%$ and $20.5 \%$ respectively. The increasing trend from wave 1 to wave 2 in salience of PHWs was statistically significant.

\section{Avoidance behavior}

In general, about $29 \%$ of respondents reported that they had made attempts to avoid looking or thinking about the PHWs within the last month prior to the interview. In particular, respondents claimed that they are trying to avoid the PHWs by various methods. Detail of those avoidant actions was illustrated in Table 2. The most common avoidant actions were "keeping the pack out of sign" (44.3\%), "covering the warnings up including using a cigarette case" $(37.6 \%)$. Other methods mentioned were "move the cigarettes to other pack which does not have the PHW" (14.4\%), "tear off the PHW" (6.7\%), "only buy packs without PHWs" (4.8\%), and "only buy cigarette separately instead of buying the whole pack" $(2.6 \%)$.

Between wave 1 and wave 2, proportion of respondents who try as well as have specific actions to avoid PHWs were statistically significant different (chi-square test) with decrease trend from wave 1 to wave 2 . For example, the

Table 2. Respondents' Avoidant Behaviors Towards the PHWs Across 2 waves of the Study

\begin{tabular}{|c|c|c|c|c|}
\hline & Wave 1 & Wave 2 & Total & p-value* \\
\hline Made effort to avoid PHWs within the last month & 35 & 23 & 28.9 & $<0.001$ \\
\hline \multicolumn{5}{|l|}{ Specific actions to avoid the PHWs } \\
\hline Covering the warnings up & 25.5 & 23.1 & 24.5 & NS \\
\hline Keeping the pack out of sight & 47 & 40.3 & 44.3 & NS \\
\hline Using a cigarette case & 15.8 & 9.2 & 13.1 & 0.01 \\
\hline Move the cigarettes to other pack which does not have the PHW & 17.8 & 9.5 & 14.4 & 0.001 \\
\hline Tear off the PHW & 4.9 & 9.2 & 6.7 & 0.013 \\
\hline Only buy packs without PHWs & 5.9 & 3.2 & 4.8 & NS \\
\hline Only buy cigarette separately (instead of buying the whole pack) & 3.2 & 1.7 & 2.6 & NS \\
\hline
\end{tabular}

NS: not significant; * Results of chi-square test comparing between wave 1 and wave 2

Table 3. Respondents Selection of Cigarette Pack with and without PHWs in Some Hypothetical Scenarios Across 2 Waves Of The Study

\begin{tabular}{|c|c|c|c|c|}
\hline & Wave 1 & Wave 2 & Total & p-value* \\
\hline \multicolumn{5}{|c|}{ Pack selection if both 2 types of pack with and without PHWs were available in the shop at the same price } \\
\hline Buy the pack with PHWs & 10.3 & 19.2 & 14.9 & \multirow{4}{*}{$<0.001$} \\
\hline Buy the pack without PHWs & 62.4 & 48.7 & 55.4 & \\
\hline Don't mind (both types are fine) & 25.3 & 30.5 & 27.9 & \\
\hline Don't know/not sure & 2.0 & 1.6 & 1.9 & \\
\hline \multicolumn{5}{|c|}{$\begin{array}{l}\text { Pack selection if both } 2 \text { types of pack with and without PHWs were available in the shop and the pack without PHWs had } \\
\text { higher price }\end{array}$} \\
\hline Buy the pack with PHWs & 34.0 & 39.0 & 36.5 & \multirow{4}{*}{$<0.001$} \\
\hline Buy the pack without PHWs & 42.7 & 35.6 & 39.1 & \\
\hline Don't mind (both types are fine) & 19.7 & 22.8 & 21.3 & \\
\hline Don't know/not sure & 3.6 & 2.6 & 3.1 & \\
\hline \multicolumn{5}{|c|}{ Pack selection in case in the tobacco shop/vender, respondent's regular brand has only the packages with PHWs } \\
\hline Still buy preferred brand that the packages have PHW & 55.9 & 73.1 & 64.6 & \multirow{4}{*}{$<0.001$} \\
\hline Buy another brand of cigarette that its package does not have PHW & 27.4 & 17.0 & 22.1 & \\
\hline $\begin{array}{l}\text { Go elsewhere to buy the smuggled cigarette of the preferred brand (that } \\
\text { do not have the PHWs on its package) }\end{array}$ & 7.6 & 5.0 & 6.3 & \\
\hline I don't know/I am not sure & 9.1 & 4.9 & 7.0 & \\
\hline
\end{tabular}

NS: not significant; * Results of chi-square test comparing between wave 1 and wave 2 
Table 4. Odds Ratios for Intention to Quit in Relation to Demographic, Smoking Characteristics and PHWs related Variables Across 2 waves of the Study

\begin{tabular}{|c|c|c|c|c|c|}
\hline \multirow{2}{*}{ Characteristics } & \multirow{2}{*}{$\begin{array}{l}\% \text { individuals } \\
\text { intend to quit }\end{array}$} & \multicolumn{2}{|c|}{ Bivariate analysis } & \multicolumn{2}{|c|}{ Multivariate analysis* } \\
\hline & & OR $(95 \% \mathrm{CI})$ & p-value & OR $(95 \% \mathrm{CI})$ & p-value \\
\hline \multicolumn{6}{|l|}{ Age group } \\
\hline $18-23$ years old & 26.2 & 1.0 & NS & - & - \\
\hline 24-29 years old & 36.5 & $1.2(1.0-1.4)$ & & - & - \\
\hline 30-35 years old & 37.3 & $1.3(1.1-1.6)$ & & - & - \\
\hline \multicolumn{6}{|c|}{ No. of cigarettes smoked per day (only included daily smokers) } \\
\hline 5 cigarettes or less & 20.9 & 1.0 & & 1 & \\
\hline 6 - 14 cigarettes & 43.3 & $0.6(0.5-0.8)$ & $<0.0001$ & $0.6(0.4-0.8)$ & 0.002 \\
\hline 15 cigarettes or more & 35.8 & $0.5(0.4-0.6)$ & $<0.0001$ & $0.4(0.3-0.6)$ & $<0.0001$ \\
\hline \multicolumn{6}{|l|}{ Years as smokers } \\
\hline$\geq 15$ years & 13.9 & 1.0 & NS & - & - \\
\hline $10-14$ years & 26.1 & $1.1(0.8-1.3)$ & & - & - \\
\hline $5-9$ years & 34.5 & $1.1(0.9-1.4)$ & & - & - \\
\hline Less than 5 years & 25.6 & $1.2(1.0-1.5)$ & & - & - \\
\hline \multicolumn{6}{|l|}{ Ever made a quit attempt } \\
\hline No & 44.4 & 1.0 & & 1.0 & \\
\hline Yes & 55.6 & $4.8(4.1-5.7)$ & $<0.0001$ & $4.8(3.8-6.1)$ & $<0.0001$ \\
\hline \multicolumn{6}{|c|}{$\begin{array}{l}\text { Worry about the health consequences of } \\
\text { smoking }\end{array}$} \\
\hline Not at all worried & 17.5 & 1.0 & & 1.0 & \\
\hline A little worried & 44.9 & $2.2(1.7-2.7)$ & $<0.0001$ & $2.0(1.4-3.0)$ & 0.0002 \\
\hline Moderately worried & 21.7 & $3.4(2.6-4.4)$ & $<0.0001$ & $2.6(1.7-4.0)$ & $<0.0001$ \\
\hline Very worried & 15.8 & $9.3(6.6-13.0)$ & $<0.0001$ & $4.2(2.5-7.1)$ & $<0.0001$ \\
\hline \multicolumn{6}{|c|}{ Made any effort to avoid looking or thinking about the PHWs in last month } \\
\hline No & 71.1 & 1.0 & & 1.0 & \\
\hline Yes & 28.9 & $2.1(1.8-2.5)$ & $<0.0001$ & $1.5(1.2-2.0)$ & $<0.0001$ \\
\hline \multicolumn{6}{|c|}{ Notice the PHWs on cigarette packages } \\
\hline Once in a while & 20.4 & 1.0 & & 1.0 & \\
\hline Often & 44.4 & $1.9(1.6-2.3)$ & $<0.0001$ & $0.7(0.5-0.9)$ & 0.0142 \\
\hline Always & 35.3 & $3.7(2.9-4.6)$ & $<0.0001$ & $1.0(0.7-1.5)$ & NS \\
\hline \multicolumn{6}{|c|}{ Look closely at the pictures and read the enclosed warning messages printed on the cigarette packages } \\
\hline Once in a while & 18.1 & 1.0 & & 1.0 & \\
\hline Often & 50.7 & $2.0(1.7-2.5)$ & $<0.0001$ & $1.9(1.5-2.6)$ & $<0.0001$ \\
\hline Always & 31.2 & $4.5(3.4-6.0)$ & $<0.0001$ & $2.3(1.4-3.9)$ & 0.0016 \\
\hline
\end{tabular}

NS: Not significant; *ORs have been adjusted for no of cigarette smoke per day, ever made a quit attempt, worry about the health consequences, made effort to avoid PHWs, notice the PHWs, read the PHWs

proportion of respondents who try to avoid PHWs had decreased significantly from $34.9 \%$ in wave 1 to $23 \%$ in wave 2.

\section{Selection of pack with and without PHW}

Table 3 describes the selection of pack with and without PHWs in three hypothetical scenarios built by researchers. First scenario was when both 2 types of pack, with and without PHWs, were available at the point of sale. More than half of the respondents (55.4\%) responded that they would buy the pack without PHWs in case the price of the two types was the same. In case the pack without PHWs had higher price, $39.1 \%$ of respondents still claimed that they would buy the pack that did not have PHWs. In another scenario when at point of sale the preferred brand of smoker had only pack with PHWs, 64.6\% of respondents would buy their preferred brand regardless the PHWs on its pack while $22.1 \%$ would be willing to buy cigarette from other brands as long as that brand's pack did not have PHWs.

There were statistically significant difference in pack selection of respondents in wave 1 and wave 2 (chi-square test, $\mathrm{p}<0.001)$. Similarly to the proportion of trying to avoid PHWs, the proportion of respondents chose to buy cigarette pack without PHWs in all hypothetical scenarios (in case of availability, price and brand) showed a decline trend from wave 1 to wave 2 .

\section{Association with intention to quit}

Table 4 shows the results of multivariate analysis using a logistic regression model. Although it was not presented in this table, bivariate analysis was carried out and included the co-variables "occupation", "monthly income", "urban/rural", and "education". No statistical 
significant associations were observed between these covariables mentioned in relation to PHWs and therefore, they were not included in the logistic regression model.

The result from bivariate analysis showed that "No of cigarette smoke per day", "Ever made a quit attempt", "Worry about the health consequences of smoking", "Made any effort to avoid the PHWs", "Notice the PHWs", and "Read the PHWs" were significantly associated with intention to quit of all respondents.

Different from bivariate analysis, "Notice the PHWs on cigarette" was no longer association with intention to quit in the multivariate analysis. The two strongest predictors for a quit intention were "Ever made a quit attempt" (adjusted OR=4.8, 95\%CI: 3.8-6.1) and "Very worried about the health consequences of smoking" (adjusted $\mathrm{OR}=4.2,95 \% \mathrm{CI}: 2.5-7.1)$. Other predictors are "Made effort to avoid PHWs" (adjusted OR=1.5,95\%CI: 1.2-2.0), "always read the PHWs" (adjusted OR=2.3, 95\%CI: 1.43.9). In contrast, "smoke $>15$ cigarette per day" reduce the odds of presenting intention to quit significantly (adjusted $\mathrm{OR}=0.4$, 95\%CI: $0.3-0.6$ ).

\section{Discussion}

In general, results from the present study indicate a relative strong association between "tried to avoid looking or thinking about the PHWs" and high level of quit intention. Predictors include "ever made a quit attempt", "concern about the health consequences of smoking".

In this repeated cross-sectional study, demographic information of respondents in two waves was consistent. Demographic and smoking characteristic (age when start smoking, no. of cigarette smoke per day, proportion of daily smokers) reported by this study was also similar with the results of Vietnam Global Adult Tobacco Survey (GATS) 2010 with national representative sample (Vietnam Ministry of Health et al., 2010). Hence, the results not only represent for the 6 study sites but might be generalized to smokers in other geographical areas of Vietnam. However, it is worth to note that the research is limited to the group of male smoker in the age group 18-35 years, thus the results may not be generalized to other age groups of smokers.

According to Australian research, response to the new warnings would reach its peak levels shortly after the implementation (Borland and Hill, 1997). In case of Australia, their new PHWs reach their peak level of impact just 1 year after the implementation and then started decreasing (Australian Institute of Health and Welfare, 2004; Australian Institute of Health and Welfare, 2010). In our study in Vietnam, salience of PHWs 2 years after the implementation was higher compared to 1 year after the implementation which may be explained by the more presence of PHWs in the market. One year post implementation, the transition period has just shortly ended as official deadline for tobacco manufacturers to print PHWs on all their products are 6 and 10 months in case of soft and hard pack respectively (Vietnam Ministry of Health and Vietnam Ministry of Industry and Trade, 2013). Thus, at this point, pack without PHWs on the market still circulated with remarkable number.

Without at least another wave of the research, we cannot conclude that salience of PHWs in Vietnam reach their peak level 2 years after the implementation. Because the extent of PHWs' wear-out is differ from country to country and depends on the specific PHWs implemented (Moodie et al., 2013; White et al., 2014; Auemaneekul et al., 2015; Li et al., 2015), it is important to find out how long the salience may reach its peak in Vietnam to determine the appropriate time for rotation cycle and routinely refreshing the PHWs. For instance, the set of PHWs is changed every 12 months in Belgium, Australia, New Zealand and every 24 months in Switzerland (Canadian Cancer Society, 2010). In addition, antismoking campaigns especially on mass media should be done periodically to support the salience of PHWs.

In wave 1, respondents tended to buy the pack without PHWs. Even when the pack without PHW has higher price, still more smokers claimed that they would buy it rather than the pack having PHW (42.7\% compared to $34.0 \%$ ). When time passed by, respondents became less willing to buy the cigarette pack without PHWs if it is not available at the time of buying or is more expensive compared with cigarette pack that have PHWs.

This decline trend may be caused by the familiarity of smokers with the PHWs after a period of implementation. At the time of wave 2-2 years after the implementation of PHWs - the limited number of packs without PHWs on the market and the acceptance of smokers on the reality that "cigarette pack has to have PHWs" may also influence their selection of pack in our hypothetical scenarios.

The proportion of respondents who did "make effort to avoid PHWs within the last month" at wave 1 was sharply higher than this proportion at wave 2. It could be explained that at first they were not familiarized with PHWs so that these pictures had stronger effect on customers and then time by time people got used to seeing them on cover of tobacco package so that they did not try to avoid PHWs.

It was very interesting to observe that "tried to avoid looking and thinking about the PHWs" increased the risk of presenting quit intention by approximately 1.5 times as compared to those respondents who were not trying to avoid looking and thinking about the PHWs. The present study is not the first to have observed a positive association between avoidance of PHWs and quit intention. Similar results were reported by Fathelrahman et al. (2013) and Borland et al. (2009b). However, in the mentioned studies the observed associations did not remain statistically significant after adjustment for confounding (Borland et al., 2009b; Fathelrahman et al., 2013). While our logistic regression model contains both concern about health and avoidance of PHWs, we assume that these two variables could be interlinked. In other words, avoidance of the warnings is associated with quit intention through the level of worrying about the harms. All in all, the findings in the present study suggest that avoidance regarding PHWs is not working as a barrier when aiming at higher level of quit attention. Those who sometimes try to avoid looking at or thinking about the PHWs tend to think more about quitting. 
Along with the effort to avoid the PHWs (avoidance), previous attempt to quit smoking, level of worrying about health consequences and always read the PHWs were also associated with intention to quit. The association between those factors and intention to quit has also been observed in other studies (Hammond et al., 2003; Borland R et al., 2009a; Borland R et al., 2009b; Feng et al., 2010; Panda et al., 2014). A smoker who attempted to quit in the past but failed may obtain new motivation from the PHWs and want to try again. Likewise, smokers with a high level of concern about the consequences of smoking can find the shocking and fear-arousing images about smoking-related diseases on the PHWs as a "push" to develop quit intention and make quit attempt.

Literature from US, Australia, Canada, UK and China showed that the heaviness of smoking is a significant barrier to making quit attempt. Specifically, among smokers, the more number of cigarettes smoke per day, the lower the willingness to quit (Hyland et al., 2004; Hyland et al., 2006; Fagan et al., 2007; Feng et al., 2010). Our study found the similar results as smokers who smoke 15 cigarettes or more per day had the odds of developing intention to quit 0.4 times lower than those who smoke less than 5 cigarettes per day.

In conclusion, despite limitations in the design, this is the first study in Vietnam assessing the salience of PHWs and pattern of smokers' reaction to PHWs overtime. Contributing to the growing pool of evidences about PHWs' salience and their long-term effect, the study may also function as rationale for implementation of further studies in Vietnam specifically focusing on PHWs. It may also be used by policy makers to determine the most appropriate requirements on rotation cycle and routinely refreshing the set of PHWs in Vietnam. As the salience of PHWs is reaching its peak and will decline after that, the highest priorities are to maintain and enhance the salience of PHWs in particular and the impact of PHWs in general through anti-smoking campaign using the image of PHWs, using of a new set of PHWs, using of larger PHWs on the pack, or use of plain packaging, for example.

\section{Acknowledgements}

The authors acknowledge the support and collaboration from the Vietnam Public Health Association in data collection of this study, the Commune People Committees and commune health stations in all study sites for allowing and providing logistic support to conduct the study. We also would like to express our sincere appreciations to Dr. Malcolm Moore, the Editor in chief of the Asian Pacific Journal of Cancer prevention, for his great input to this paper. The authors would also like to thank the anonymous reviewers for their valuable comments that strengthened this paper.

\section{References}

Auemaneekul N, Silpasuwan P, Sirichotiratana N, et al (2015). The impact of cigarette plain packaging on health warning salience and perceptions: implications for public health policy. Asia Pac J Public Health, 27, 848-59.
Australian Institute of Health and Welfare (2004). National Drug Strategy Household Survey: detailed findings. Canberra: AIHW cat. no. PHE 66.

Australian Institute of Health and Welfare (2010). National Drug Strategy Household Survey: survey report. Canberra: AIHW cat. no. PHE 145.

Borland R, Wilson N, Fong GT, et al (2009a). Impact of graphic and text warnings on cigarette packs: findings from four countries over five years. Tob Control, 18, 358-64.

Borland R, Yong HH, Wilson N, et al (2009b). How reactions to cigarette packet health warnings influence quitting: findings from the ITC Four-Country survey. Addiction, 104, 669-75.

Borland R, Hill D (1997). Initial impact of the new Australian tobacco health warnings on knowledge and beliefs. Tobacco Control, 6, 317-25.

Canadian Cancer Society (2010). Cigarette Package Health Warnings - International Status Report. Canada.

Elton-Marshall T, Xu SS, Meng G, et al (2015). The lower effectiveness of text-only health warnings in China compared to pictorial health warnings in Malaysia. Tobacco Control, 24, 6-13.

Fagan P, Augustson E, Backinger CL, et al (2007). Quit attempts and intention to quit cigarette smoking among young adults in the United States. Am J Public Health, 97, 1412-20.

Fathelrahman AI, Li L, Borland R, et al (2013). Stronger pack warnings predict quitting more than weaker ones: finding from the ITC Malaysia and Thailand surveys. Tobacco Induced Diseases, 11, 20.

Fathelrahman AI, Omar M, Awang R, et al (2010). Impact of the new Malaysian cigarette pack warnings on smokers' awareness of health risks and interest in quitting smoking. Int J Environ Res Public Health, 7, 4089-99.

Feng G, Jiang Y, Li Q, et al (2010). Individual-level factors associated with intentions to quit smoking among adult smokers in six cities of China: findings from the ITC China Survey. Tobacco Control, 19, 6-11.

Hammond D (2007). Tobacco labelling and packaging: A review of evidence. International Union Against Tuberculosis and Lung Disease.

Hammond D (2009). Tobacco labelling and packaging toolkit: A guide for FCTC Article 11. Ottawa, Canada: University of Waterloo. Department of Health Studies.

Hammond D (2011). Health warning messages on tobacco products: a review. Tob Control, 20, 327-37.

Hammond D, Fong G T, McNeill A, et al (2006). Effectiveness of cigarette warning labels in informing smokers about the risks of smoking: findings from the International Tobacco Control (ITC) Four Country Survey. Tobacco Control, 15, 19-25.

Hammond D, G T Fong, P W McDonald, et al (2003). Impact of the graphic Canadian warning labels on adult smoking behaviour. Tobacco Control, 12, 391-5.

Hyland A, Borland R, Li Q, et al (2006). Individual-level predictors of cessation behaviours among participants in the International Tobacco Control (ITC) Four Country Survey. Tobacco Control, 15, 83-94.

Hyland A, Li Q, Bauer JE, et al (2004). Predictors of cessation in a cohort of current and former smokers followed over 13 years. Nicotine Tobacco Res, 6, 363-9.

International Tobacco Control Policy Evaluation Project. Countries report: China summary report. 2009.

Li L, Borland R, Yong H, et al (2015). Longer term impact of cigarette package warnings in Australia compared with the United Kingdom and Canada. Health Educ Res, 30, 67-80.

Miller CL, Hill DJ, Quester PG, et al (2009). Impact on the Australian Quitline of new graphic cigarette pack warnings including the Quitline number. Tobacco Control, 18, 235-7.

Moodie C, Mackintosh AM, G.H (2013). Adolescents' response 


\section{Tran Thu Ngan et al}

to pictorial warnings on the reverse panel of cigarette packs: a repeat cross-sectional study. Tobacco Control, 1-5.

National Assembly of Vietnam. Law on Prevention and Control of Tobacco Harms. 09/2012/QH13. Government document. Language: Vietnamese.

Nguyen NB, Do MS (2006). The views of consumers about the health warnings on cigarette packets. Vietnam J Public Health, 5, 8-14.

O'Hegarty M, Pederson LL, Yenokyan G, et al (2007). Young adults' perceptions of cigarette warning labels in the United States and Canada. Prev Chronic Dis, 4, A27.

Panda R, Venkatesan S, Persai D, et al (2014). Factors determining intention to quit tobacco: exploring patient responses visiting public health facilities in India. Tobacco Induced Diseases, 12, 1-4.

Sychareun V, Hansana V, Phengsavanh A, et al (2015). Perceptions and acceptability of pictorial health warning labels vs text only - a cross-sectional study in Lao PDR. BMC Public Health, 15, 1094.

Tan YL, Ulysses D (2013). The ASEAN tobacco control atlas. Bangkok, Thailand: Southeast Asia Tobacco Control Alliance (SEATCA).

Vardavas CI, Connolly G, Karamanolis K, et al (2009). Adolescents perceived effectiveness of the proposed European graphic tobacco warning labels. Eur J Public Health, 19, 212-7.

Vathesatogkit P (2010). Article 11 (Packaging and Labelling of Tobacco products) Guidelines, Thailand, Action on Smoking and Health Foundation (ASH).

Vietnam Ministry of Health, Hanoi Medical University, General Statictis Office, et al Global Adults Tobacco Survey GATS Vietnam final report 2010. Hanoi, Vietnam: 2010. Language: English.

Vietnam Ministry of Health, Vietnam Ministry of Industry and Trade. Joint Circular guiding the labeling, printing pictorial health warnings on cigarette packages. 05 /2013/TTLT-BYTBCT. Government document. Language: Vietnamese.

White V, Bariola E, Faulkner A, et al (2014). Graphic health warnings on cigarette packs: how long before the effects on adolescents wear out? Nicotine Tobacco Res 17, 776-83.

World Health Organization (2005). Framework Convention on Tobacco Control (FCTC), Geneva, Switzerland, WHO Press.

World Health Organization 2008. WHO report on the global tobacco epidemic: The MPOWER package, Geneva, Switzerland, WHO Library Cataloguing-in-Publication Data. 